\title{
From the Editors: Explaining theoretical relationships in international business research: Focusing on the arrows, NOT the boxes
}

\author{
David C Thomas ${ }^{1}$, \\ Alvaro Cuervo-Cazurra ${ }^{2}$ \\ and Mary Yoko Brannen ${ }^{3}$ \\ ${ }^{1}$ Area Editor; ${ }^{2}$ Reviewing Editor; \\ ${ }^{3}$ Deputy Editor \\ Correspondence: \\ DC Thomas, Beedie School of Business, \\ Simon Fraser University, 500 Granville \\ Street, Vancouver, BC, Canada V6C 1W6. \\ Tel: + 17787827709 ; \\ Fax: + 1778782 5122; \\ Email: dcthomas@sfu.ca
}

\begin{abstract}
Distinctive features of articles accepted by the Journal of International Business Studies are that they are multidisciplinary in scope and interdisciplinary in content and methodology, and they make a substantial theoretical contribution to international business studies. Failure to meet this last requirement is an often cited reason given by reviewers for article rejection. Sometimes reviewers mean that a manuscript does not conform to the dominant paradigm, in that it is not the next logical step in the study of a phenomenon, or they mean that there is little if any integration of several theories used to explain a phenomenon. However, perhaps the most common underlying meaning when reviewers cite "lack of a theoretical contribution" for rejection is that the nature of the relationships proposed is not well explained. While the first two meanings may be influenced by the specific discipline or methodology involved, this final one is not. In this editorial we provide a set of guidelines that authors can use to ensure that their paper meets the standard of explaining the logic of the relationships they propose.
\end{abstract}

Journal of International Business Studies (2011) 42, 1073-1078.

doi: | 0. 1057/jibs.201 I.44

Keywords: theory; mechanisms; international business

"What is important [...] is not knowledge of particulars but knowledge of the relations among phenomena". (Kerlinger, 1986: 55)

\section{INTRODUCTION}

As the title of this editorial implies, many international business scholars think in terms of conceptual diagrams consisting of boxes and arrows to inform our research. Boxes of course represent concepts, constructs or variables, and arrows represent the relationships among them. Figure 1 illustrates a typical diagram in which constructs of interest are linked by arrows. Thinking in terms of such diagrams can help organize relationships in a logical order, understand how concepts intervene or moderate and even describe how a process unfolds over time. They can provide structure to amorphous concepts and highlight inconsistency in arguments. However, as useful as they can be, diagrams are only "stage props rather than the performance itself" (Sutton \& Staw, 1995: 376). That is, we are not suggesting that such diagrams are required, but they are presented as a vehicle to clearly specify theoretical 


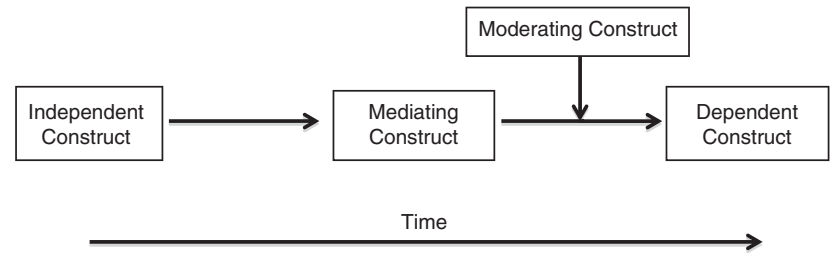

Figure 1 Typical conceptual diagram.

relationships. Others, for example, may use metaphor or discourse as opposed to such diagrams to inform their thinking. What is important is that the logic of the relationships depicted in the arrows is clearly articulated in the manuscript.

Unfortunately, a large number of submitted papers fail to make clear this logic and are thus deemed by reviewers and editors to lack a theoretical contribution. In the following we identify some common errors or shortcomings found in papers, discuss how the international context adds another layer of complexity to the explanation of relationships while providing opportunities for theory development and conclude with suggestions on how to identify if a paper has adequately explained the logic of proposed relationships.

\section{COMMON PROBLEMS IN FAILING TO EXPLAIN RELATIONSHIPS}

While clearly stating relationships may seem a straightforward process, numerous manuscripts submitted to the Journal of International Business Studies (JIBS) lack this important element, often overemphasizing or substituting other important but insufficient elements. ${ }^{1}$ Specifically, what is often used in lieu of the careful explanation of logical relationships among concepts required by JIBS are: lists and definitions of constructs, descriptions of observed patterns of empirical evidence and references to previous literature. Even mathematical modeling papers, whose value may lie primarily in the elegance of the model, need to clearly explain their intuition to make them accessible to the broader JIBS readership.

\section{Describing Constructs and Hoping for Magic}

First, papers submitted to JIBS sometimes seem to assume that describing the set of constructs or variables studied is sufficient theoretical development and that the relationships among concepts will appear - as if by magic. Statements such as "Antecedents of $B$ include $A_{1}, A_{2}$ and $A_{3}$ " do not constitute theory no matter how well $\mathrm{A}_{1}, \mathrm{~A}_{2}$ and $\mathrm{A}_{3}$ are described. The specification of concepts, constructs or variables is an important element in describing a phenomenon at a higher level of abstraction than reality. These generalized ideas are given names to represent classes of objects, attributes or processes that provide the building blocks of theory. Constructs must be broad enough to reflect the domain of the phenomenon being studied, but be also parsimonious enough to focus inquiry (Bacharach, 1989). Their clear, precise, and succinct definition is an important part of theory development (see Feldman, 2004). New constructs must be shown to add value above and beyond existing constructs. And the manner in which constructs resulting from the combination of lower order elements are formed must be specified (Chan, 1998).

While the specification of constructs is an important element in theory construction, authors cannot assume that readers will somehow automatically understand how the constructs are related to or build on each other. A thorough discussion of the constructs results in a deepening of the understanding of the constructs but not of the relationship among them. What must be clear is how and why constructs influence each other, the logic of the direction of the relationship specified and under what conditions the relationship is predicted to exist.

Sometimes (often in large sample papers) long lists of constructs seem to be an attempt to cover all of the possible antecedents of a particular outcome (see Sutton \& Staw, 1995). These lists of constructs are often submitted to sophisticated analysis techniques, which may mirror conceptual diagrams such as presented in Figure 1. However, statistical packages, no matter how sophisticated, are not a substitute for the logical development of relationships. It is authors, not the statistical tool, who define which variables are independent, dependent, mediating or moderating, and why and how they are related. What is required is a clear explanation of how these constructs came about, and the character and direction of their relationship. It is also important to recognize that even in cases where strong causal logic is specified in the theoretical development, the ability to establish causality through statistical means is limited (McGrath, 1982).

The need to explain how concepts relate to the building of strong theory is equally important in qualitative analysis (cf. Birkinshaw, Brannen, \& Tung, 2011). In fact, construct induction is the sine qua non of grounded theory where a careful 
methodology of constantly comparing and contrasting extant theory with field data yields new theoretical contributions (Glaser \& Strauss, 1967). As Weick (1995: 390) states, "ungrounded theory is no more helpful than are atheoretical data."

\section{Reporting Empirical Regularities and Relying on Repetition}

Second, other papers describe previously reported empirical results as the sole evidence that the relationships that inform their study exist (what Weick, 1995, called grafting theory onto stark sets of data). That is, statements such as "Study X found that $A_{1}$ was directly and positively related to $\mathrm{B}_{1}$, which was corroborated in a study by Author Y. Therefore we predict that ..." are insufficient as explanations. Observed consistencies in data such as correlations, beta weights, factor loadings or statements by informants describe what empirical patterns have been observed but not why they were found or can be expected (Kaplan, 1964). That is, we do not learn from observation of previous empirical findings why we should predict similar patterns in the future, especially in international business research. Understanding and explaining the logic of the consistent patterns found or observed is required. While there is some regularity in human behavior that can inform research, often referred to as law-like generalizations, these regularities are subject to validation in the international context as discussed ahead.

Explaining why consistent patterns are observed in qualitative data may be even more important than it is in quantitative data (see Eisenhardt, 1991; Glaser \& Strauss, 1967). As the objective of these studies is often to inform rather than to test theory, authors need to explain how constructs have emerged from the coding and analysis of qualitative data and also to specify how and why the observed patterns of empirical results are logically related.

\section{Citing Established Theories and Assuming Something Will Fit}

Finally, some papers rely solely on citations to existing theories and previous studies to inform their research. For example, statements such as "Based on XYZ theory we predict that $A_{1}$ will affect $\mathrm{B}_{1}$ " or "Based on the findings in Often Cited Study $\mathrm{K}, \mathrm{A}_{1}$ will predict $\mathrm{B}_{1}$ " are inadequate. Referring to prior theory helps to identify with whom the author is establishing an intellectual conversation and, of course, gives credit to the body of work on which the author intends to build. However, while it is important to acknowledge previous work on which the study draws, simply naming the theories and citing key publications is not the same as articulating the logic that informs the relationship among constructs.

In some cases references obfuscate relationships and are used to conceal the fact that the author really does not understand the phenomenon in question (Sutton \& Staw, 1995). Often a close examination of works cited reveals that authors have not really understood the logic of the papers to which they refer. This is particularly evident in so-called ritual citations that authors feel obligated to make in order to demonstrate that they are a qualified member of the discipline. In addition, references to work that seems to be pertinent because it carries a similar label to the topic being studied, but without a clear understanding of the logic and basic assumptions, do not provide solid ground for establishing relational logic. Often it seems that long lists of citations (sometimes after every phrase) are made under the assumption that something in the articles being cited will fit within the general theme of the manuscript. In many cases if these citations are deleted from the manuscript, the arguments become merely a set of unconnected phrases lacking logic (see Sutton \& Staw, 1995).

References to concepts and causal arguments from previous work are important, but how and why these arguments are linked to the theory being developed or tested must be clearly explained. Clarity with regard to references to prior work helps to establish the author's unique contribution and also to develop a theoretical path trajectory for the field. This is especially critical in a low paradigm field (Sutton \& Staw, 1995) such as international business where the next step in the dominant logic is not pre-established. Tempting though it may be to use pre-established models and necessary as it may be to use simple structures to describe relationships, embedded in these is the assumption that the structure of the underlying process being described is stable over time and space. Most processes undergo change over time, and many components of structures co-evolve with one another in a wider complex and interconnected social system. So while theories need to be simple, in theory development authors need to acknowledge where appropriate that they are focusing on just one aspect of a wider process, and then to provide some justification for why this particular aspect or line of argument is believed to be an especially important, prominent or significant aspect of that wider reality. 
These three general problems are central to the articulation of clear relationships among concepts, constructs and variables, and they are common to all disciplines. The international business context, while offering the potential to extend theory in a manner that domestic studies cannot, adds another layer of complexity to these more general issues in relationship specification. JIBS editorial policy requires the international aspect of the paper be integral to the relationships presented.

\section{THE CHALLENGING CONTEXT OF INTERNATIONAL BUSINESS}

JIBS manuscripts must answer the question of exactly how the international context advances our understanding over what happens in a purely domestic environment. The domain of international business, according to the JIBS Statement of Editorial Policy, consists of "(1) the activities, strategies, structures and decision-making processes of multinational enterprises (MNEs); (2) interactions between MNEs and other actors, organizations, institutions, and markets; (3) the cross-border activities of firms (e.g., intrafirm trade, finance, investment, technology transfers, offshore services); (4) how the international environment (e.g., cultural, economic, legal, political) affects the activities, strategies, structures and decision-making processes of firms; (5) the international dimensions of organizational forms (e.g., strategic alliances, mergers and acquisitions) and activities (e.g., entrepreneurship, knowledge-based competition, corporate governance); and (6) cross-country comparative studies of businesses, business processes and organizational behavior in different countries and environments." Additionally, an essential requirement of a manuscript is that "at least one of the six sub-domains listed above is a primary focus of attention within the main line of argument being developed in the paper. The major theme of a JIBS paper should highlight the insights that can be derived for the international aspects of business activity as such."

Thus, the international context creates additional challenges for developing theory, but at the same time it creates unique opportunities, because it can affect all of the components of the conceptual model presented in Figure 1. The relationships analyzed, the specific constructs studied, the combination of relationships and constructs and even the process and time component in the relationships can be influenced by the international business context. Building on previous work that identifies the influence of context (Brannen,
2004; Johns, 2006; Peterson \& Thomas, 2007; Roth \& Kostova, 2003), we present the following outline for specifying the effect of the international context. While not entirely orthogonal, the three broad categories for the influence of international context are: (1) extending (validating) existing theory to the international context, (2) examining functional relationships that are unique to the international context and (3) developing new theory from the international context.

\section{Extending Existing Theory}

The simplest category of specifying the effect of the international context is in the extension of existing theory to the international setting. The international context produces a condition in which more heterogeneity and complexity allows for more rigorous testing of theories or expanding their boundary conditions. That is, crossing national boundaries introduces increased variability in institutional, socio-cultural, geographic, economic, legal and political environments. Additionally, MNEs offer considerable variance in terms of strategy, governance and management practices. This creates opportunities to push the boundaries of existing theory.

However, just because a theory has not been tested in an international or MNE context does not mean it should be or that it will produce new insights. Replicating studies grounded in a domestic context in an international context does not necessarily make a contribution to international business studies. It is incumbent on authors using this approach to specify how and why increased variability in predictors and/or criteria affects existing relationships. The possible existence of universal theory (particularly economic theory, see Forsgren, 2008; Hennart, 2001) notwithstanding, authors must specify what it is about variance in the national environment or in the MNE that would cause us to believe that this context has an influence on the phenomenon of interest. For example, Bresman, Birkinshaw, and Nobel (2010) show how the specific context of international acquisitions influences knowledge transfer among business units.

\section{Examining Unique Functional Relationships}

A second category of the effect of international contexts is functional relationships that differ as a result of occurring in the international context. That is, the context produces a qualitative shift in the phenomenon so that it is substantially different or does not exist outside this context. Sometimes 
this shift results from the increased variance of the international context (discussed previously) if this variance is so extreme as to create a cusp or tipping point. In other cases, distinctive aspects of the international or MNE context change the nature of the relationship among constructs, in that the logic of the relationship between constructs differs from country to country. Often, multiple theoretical perspectives are drawn upon to explain the phenomenon and/or moderators introduced to explain the effect of context.

In this case it is important to describe the distinct characteristics of the international or MNE context that makes the relationships under study unique. That is, what are the attributes of the international environment or MNE context that define the relationship? For example, George, Jones, and Gonzales (1998) model the effect of national culture in crosscultural negotiation. They show how cultural characteristics might influence affect, which in turn influences information processing in the negotiation process.

\section{Developing New Theory}

The international context of business is ripe for new theory development involving unique constructs. Thus, the final category of influence involves the development of theory to explain phenomena that emanate from the international or MNE context. While insights may be drawn from existing theory, the international or MNE context requires a new causal logic to explain relationships. Unique constructs may be identified that are consistent with this new logic.

In this case authors must highlight why and how the international context limits the explanatory ability of existing theory in order to set the stage for alternative explanations involving new relationships and new constructs. These alternative explanations must have their own unique internally consistent logic based on the differing assumptions of the international or MNE context. For example Kwok and Reeb (2000) develop a new theory (the upstream-downstream hypothesis) to explain how internationalization affects risk and leverage in stable vs unstable economies.

A final consideration that affects all three types of influence is that context often operates across levels. These cross-level effects are most often seen as higher level contextual elements influence lower levels of meaning and relationships (Johns, 2006) or when lower level constructs are combined to form a higher level concept. Much has been written about the theoretical and methodological issues associated with studying cross-level effects (and a detailed examination of this topic in international business research will be presented in a future issue of JIBS). Therefore, here we offer only the reminder that when a relationship crosses levels of analysis, the logic of the argument must indicate how (through what mechanisms) this occurs. For example, if a relationship between societal characteristics and organizations is proposed, then the mechanisms through which these characteristics influence organizations must be explicitly stated. Simply showing that organizations vary across societies is not instructive in itself. Also, if lower level constructs are combined, the method through which they create a higher order concept must be specified. That is, are the lower order elements added or multiplied, or does the higher order latent construct emerge in some way (Chan, 1998)?

\section{EXPLAINING MECHANISMS: CAUSAL LOGIC CHECKLIST}

An often recommended, but perhaps rarely followed, piece of advice with regard to checking the logical articulation in a manuscript is to seek friendly reviews from scholars not in the same research niche. The lack of the explicit specification of relationships is often clearer to those not intimately familiar with the topic area.

To aid this review we offer the following checklist. It is not meant to substitute for the skill of constructing a cogent argument but is simply a reminder not to overlook anything. Some of the items relate to the relational logic in any type of theorizing, while others are specific to making a contribution to international business research. In reviewing your manuscript prior to submission you should ask yourself and your peer reviewers the following questions:

1. Are the concepts/constructs/variables universal, distinctly international or grounded in indigenous contexts and thus differentiated from similar domestic concepts/constructs/variables?

2. Is the method of aggregation (emergence) of composite constructs specified? For constructs derived from qualitative data, is the method of coding and within method triangulation clear?

3 . Are the theory and arguments internally consistent (coherent, logical) and applicable in the international context?

4. Are the assumptions and boundaries of the theory clearly stated and justified based on logic 
or evidence? Do they hold across countries or have they been re-specified in each country context?

5. Are deductions about the theory or conceptual development logical and clearly stated? Do these apply to the international context?

6. Are the importance, direction and magnitude of relationships (including mediators, moderators, cross level effects and the possibility of reverse causality) clearly explained?

7. Do propositions or hypotheses follow logically from the review of literature? Have alternative logics been ruled out?

8. Are basic ideas stated clearly enough to be grasped by the broad readership of JIBS?

\section{REFERENCES}

Bacharach, S. B. 1989. Organizational theories: Some criteria for evaluation. Academy of Management Review, 14(4): 496-515.

Birkinshaw, J., Brannen, M. Y., \& Tung, R. 2011. From a distance and generalizable to up close and grounded; Reclaiming a place for qualitative methods in international business research. Journal of International Business Studies, 42(5): 573-581.

Brannen, M. Y. 2004. When Mickey loses face: Recontextualization, semantic fit, and the semiotics of foreignness. Academy of Management Review, 29(4): 593-616.

Bresman, H., Birkinshaw, J., \& Nobel, R. 2010. Knowledge transfer in international acquisitions. Journal of International Business Studies, 41(1): 5-20.

Chan, D. 1998. Functional relations among constructs in the same content domain at different levels of analysis: A typology of composition models. Journal of Applied Psychology, 83(2): 234-246.

Eisenhardt, K. M. 1991. Better stories and better constructs: The case for rigor and comparative logic. Academy of Management Review, 16(3): 620-627.

Feldman, D. C. 2004. What are we talking about when we talk about theory? Journal of Management, 30(5): 565-567.

Forsgren, M. 2008. Theories of the multinational enterprise: $A$ multidimensional creature in the global economy. Cheltenham: Edward Elgar.

George, J., Jones, G., \& Gonzales, J. 1998. The role of affect in cross-cultural negotiations. Journal of International Business Studies, 29(4): 749-772.

Glaser, B. G., \& Strauss, A. 1967. The discovery of grounded theory: Strategies for qualitative research. London: Wiedenfeld and Nicholoson.
If you and your peer reviewers can answer a resounding yes to all of these questions, then the likelihood that your manuscript will pass the test of clearly presenting the relationships you propose is greatly enhanced.

\section{NOTE}

${ }^{1}$ This issue is not unique to JIBS and has been identified in other leading journals such as Academy of Management Review (Whetton, 1989), Administrative Science Quarterly (Sutton \& Staw, 1995) and Journal of Management (Feldman, 2004). However, despite these editorials in sister journals, papers submitted to JIBS continue to make similar errors, which are compounded by the cross-border nature of international business.

Hennart, J. -F. 2001. Theories of the multinational enterprise. In A. M. Rugman \& T. S. Brewer (Eds), Oxford handbook of international business: 127-149. Oxford: Oxford University Press.

Johns, G. 2006. The essential impact of context on organizational behavior. Academy of Management Review, 31(2): 386-408.

Kaplan, A. 1964. The conduct of inquiry. New York: Harper \& Row.

Kerlinger, F. N. 1986. Foundations of behavioral research. New York: Holt, Rinehart, and Winston.

Kwok, C. C. Y., \& Reeb, D. M. 2000. Internationalization and firm risk: An upstream-downstream hypothesis. Journal of International Business Studies, 31(4): 611-629.

McGrath, J. (Ed.) 1982. Dilemmatics: The study of research choices and dilemmas. In Judgment calls in research: 69-80. Beverly Hills, CA: Sage.

Peterson, M. F., \& Thomas, D. C. 2007. Organizational behavior in multinational organizations. Journal of Organizational Behavior, 28(3): 262-279.

Roth, K., \& Kostova, T. 2003. The use of the multinational corporation as a research context. Journal of Management, 29(6): 883-902.

Sutton, R. I., \& Staw, B. M. 1995. What theory is not. Administrative Science Quarterly, 40(3): 371-384.

Weick, K. E. 1995. What theory is not, theorizing is. Administrative Science Quarterly, 40(3): 385-390.

Whetton, D. A. 1989. What constitutes a theoretical contribution? Academy of Management Review, 14(4): 490-495. 